\title{
Surgical nuances for removal of retrochiasmatic craniopharyngiomas via the transbasal subfrontal translamina terminalis approach
}

\author{
James K. Liu, M.D., Lana D. Christiano, M.D., Gaurav Gupta, M.D., \\ and Peter W. Carmel, M.D. \\ Department of Neurological Surgery, University of Medicine and Dentistry of New Jersey, \\ New Jersey Medical School, Neurological Institute of New Jersey, Newark, New Jersey
}

\begin{abstract}
Giant craniopharyngiomas in the retrochiasmatic space are challenging tumors, given the location and surrounding vital structures. Surgical removal remains the first line of therapy and offers the best chance of cure. For tumors with extension into the retrochiasmatic space, the authors use the translamina terminalis corridor via the transbasal subfrontal approach. Although the lamina terminalis can be accessed via anterolateral approaches (pterional or orbitozygomatic), the surgical view of the optic chiasm is oblique and prevents adequate visualization of the ipsilateral wall of the third ventricle. The transbasal subfrontal approach, on the other hand, offers the major advantage of direct midline orientation and access to the third ventricle through the lamina terminalis. This provides the significant advantage of visualization of both walls of the third ventricle and hypothalamus as well as inferior midline access to the interpeduncular cistern to permit safe neurovascular dissection and total tumor removal. In this report, the authors describe the transbasal subfrontal translamina terminalis approach, with specific emphasis on technical surgical nuances in removing retrochiasmatic craniopharyngiomas. An illustrative video demonstrating the technique is also presented.(DOI: 10.3171/2010.1.FOCUS09309)
\end{abstract}

\section{Key Words - retrochiasmatic craniopharyngioma • transbasal subfrontal approach - lamina terminalis • surgical approach}

$\mathrm{R}$ ETROCHIASMATIC craniopharyngiomas comprise approximately $11-46 \% \%^{3,14,18,24,36,38}$ of all craniopharyngiomas, and are difficult tumors to remove because of their anatomical location. Surgical removal of these lesions has been associated with a high rate of surgery-related morbidity and mortality, as has incomplete removal resulting in higher recurrence rates. ${ }^{13,29,31,36}$ Because they are thought to arise from a supradiaphragmatic origin ${ }^{38}$ retrochiasmatic craniopharyngiomas are hidden behind the optic chiasm, and often can extend superiorly into the third ventricle and inferiorly into the interpeduncular cistern and retrosellar region. ${ }^{13,32,36}$ Surgical exposure attained using conventional operative corridors through the subchiasmatic (interoptic) or optico-carotid cisterns allows only limited and inadequate visualization of the infra- and retrochiasmatic regions, because these tumors are hidden behind an anteriorly displaced or prefixed chiasm. ${ }^{2,36}$ In essence, the optic nerves and chiasm are situated between the tumor and the surgeon, and therefore obstruct visualization and access to the retrochiasmatic region.

This has led to the development of transcranial approaches through the lamina terminalis to access retro-

\footnotetext{
Abbreviations used in this paper: $\mathrm{ACA}=$ anterior cerebral artery; $\mathrm{BA}=$ basilar artery; ICA = internal carotid artery; PCA = posterior cerebral artery; $\mathrm{PCoA}=$ posterior communicating artery; $\mathrm{SSS}=$ superior sagittal sinus.
}

chiasmatic craniopharyngiomas, which include midline (unilateral subfrontal, bifrontal, bifrontal interhemispheric) and anterolateral (pterional, orbitopterional, orbitozygomatic) routes. Other approaches to retrochiasmatic craniopharyngiomas also include transsphenoidal, extended transsphenoidal, endoscopic expanded endonasal, and posterior petrosal approaches. Each has its own advantages and disadvantages. The primary disadvantages of anterolateral approaches to the lamina terminalis include loss of midline orientation, lack of visualization of the ipsilateral wall of the third ventricle and hypothalamus (blind spot), limited oblique visualization superiorly into the third ventricle, limited visualization inferiorly into the interpeduncular cistern, and narrowing of the lamina terminalis working corridor when coming in from a lateral projection.

In our experience, we have favored midline transcranial approaches, particularly the transbasal subfrontal route, to the lamina terminalis, which addresses the disadvantages of anterolateral approaches. By coming in from a midline projection and orientation, the working corridor of the lamina terminalis is maximized and both walls of the third ventricle and hypothalamus can be adequately visualized, thereby eliminating the blind spot. There is also more superior access to the top of the third ventricle, and midline visualization inferiorly into the interpeduncular cistern. If the Liliequist membrane has not been breached by the tumor, it acts as a favorable plane of 
J. K. Liu et al.

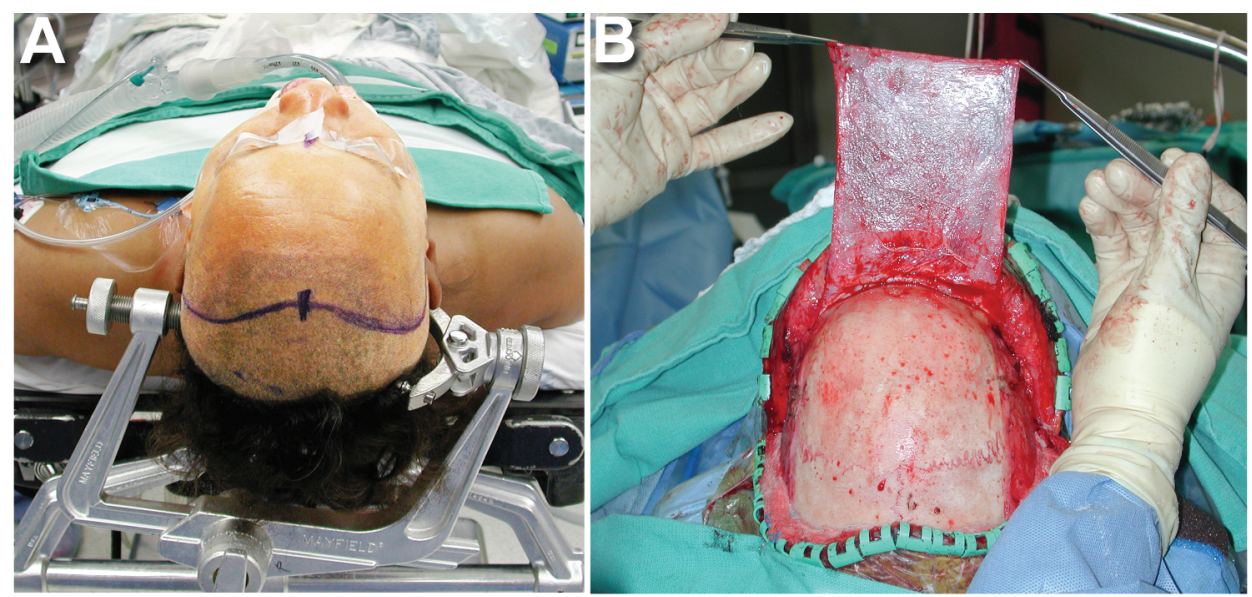

FIG. 1. A: Intraoperative photograph of the bicoronal incision that extends behind the hairline from one zygoma to the other, no more than $1 \mathrm{~cm}$ anterior to the tragus. B: Intraoperative photograph of the vascularized pedicled pericranial flap that is elevated as a separate layer for later reconstruction and closure. The posterior margin of the galeal incision is undermined posteriorly to provide additional length, to maximize the length of the pericranial flap.

dissection for removing the inferior limit of tumor in the interpeduncular cistern and retrosellar region. We believe that the transbasal subfrontal approach to the lamina terminalis is an ideal one for removing giant retrochiasmatic craniopharyngiomas that have significant intraventricular extension. In this report, we describe our technique and its operative nuances in removing these difficult lesions. An illustrative video demonstrating the technique is also presented in this report (Video 1).

VIDEO 1. Illustrative video demonstrating the surgical technique for removing retrochiasmatic craniopharyngiomas by using the transbasal subfrontal translamina terminalis approach.

\section{Surgical Technique}

\section{Patient Positioning}

A lumbar drain is placed at the start of the operation and is clamped off until further CSF drainage is needed to facilitate brain relaxation during intradural exposure of the tumor. Our neuroanesthesia team uses total intravenous anesthesia (primarily intravenous propofol and remifentanil) rather than inhalational agents, to promote further reduction of intracranial pressure and a decrease in cerebral swelling. ${ }^{10}$ The patient is positioned supine on the operating table and the head is fixed in a 3-point head holder. The bed is slightly flexed into a lounge chair position, with the patient's head and trunk elevated approximately $15-20^{\circ}$ to facilitate venous return. The neck is extended to allow the frontal lobe to fall away from the anterior skull base.

\section{Skin Incision and Harvest of Vascularized Pericranial Flap}

A bicoronal incision is used that extends behind the hairline from one zygoma to the other, no more than $1 \mathrm{~cm}$ anterior to the tragus (Fig. 1A). The scalp is elevated in a 2-layer fashion (galea and pericranial layers). Using the skin knife, the scalp is incised through the galea aponeu-

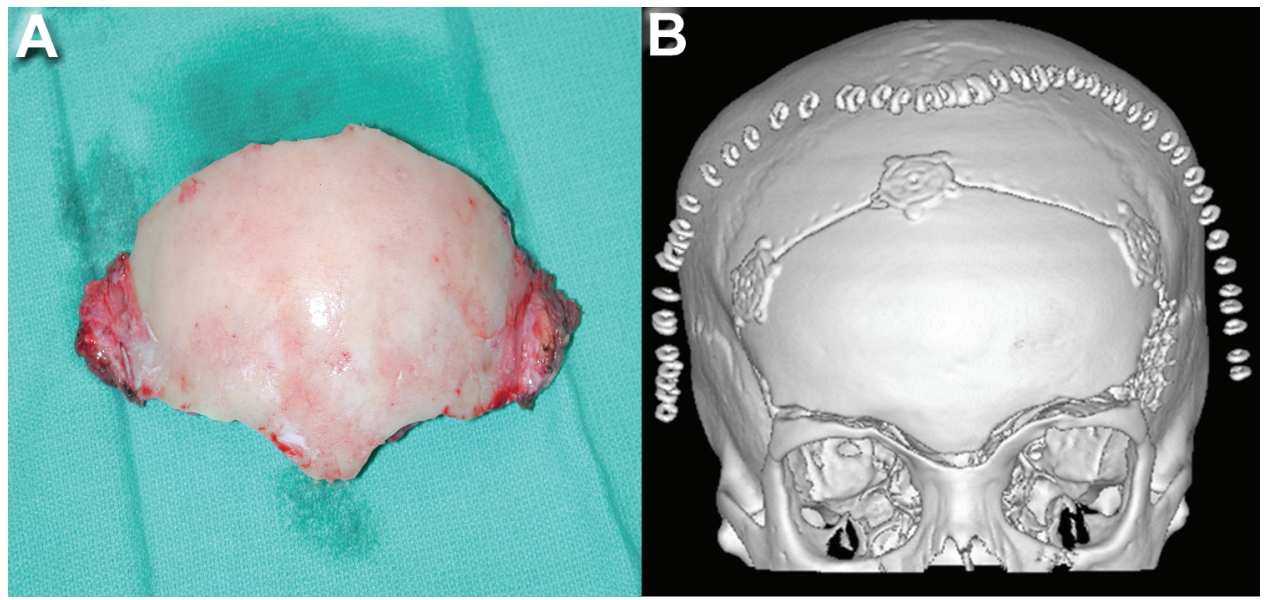

FIG. 2. A: Intraoperative photograph showing the bifrontal transbasal bone flap that incorporates the anterior wall of the frontal sinus. The inferior margin of the osteotomy is made at the nasofrontal suture and extends laterally over both orbital rims. This allows the bone flap to extend as low as possible by following the contour of the anterior skull base in the coronal orientation. B: A 3D reconstructed CT scan of the skull demonstrating the bifrontal transbasal bone flap. 


\section{Subfrontal translamina terminalis approach for craniopharyngioma}
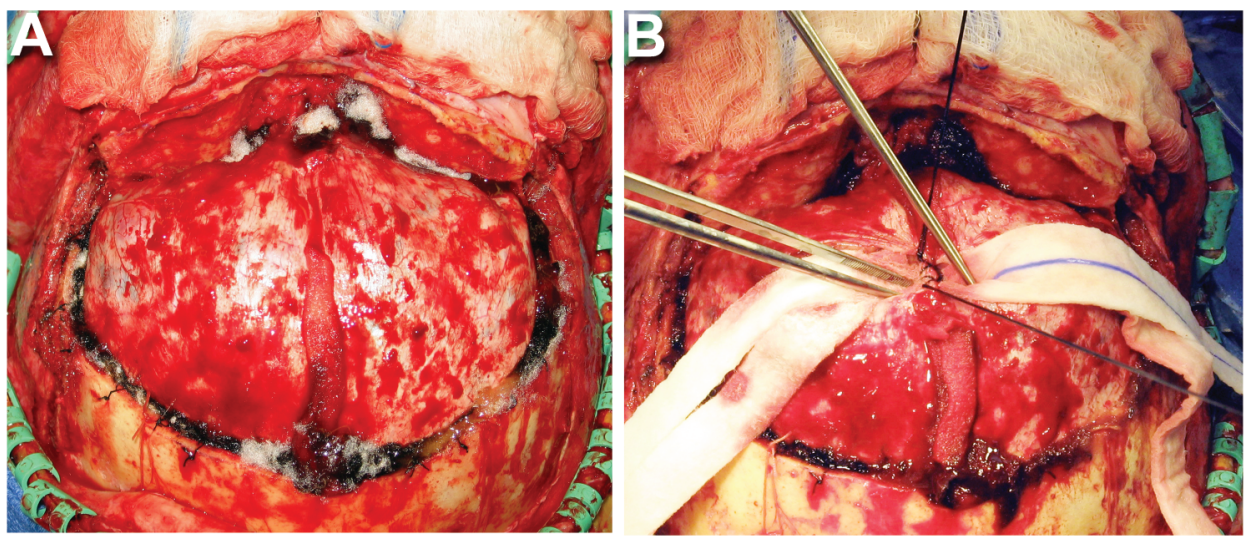

FIG. 3. A: Intraoperative photograph of the bifrontal transbasal exposure. The bone flap has been removed. The exposure is flush with the floor of the anterior skull base in the coronal orientation, and there is no bone overhang to obstruct the surgeon's line of sight to the anterior skull base. B: Intraoperative photograph demonstrating the bifrontal dural opening. Cottonoid patties are used to protect the frontal lobes during ligation and division of the SSS and falx cerebri.

rosis while sparing the pericranium. The galea layer is elevated along with the scalp anteriorly, while leaving the pericranium and temporalis muscle and fascia attached to the skull. The superficial temporal fat pad is elevated up with the galeal skin flap by using the interfascial dissection technique, as described by Yasargil et al.," preserve the frontotemporal branch of the facial nerve. Extreme care is taken to preserve the supraorbital nerve and artery as the galeal elevation approaches near the supraorbital rim. The posterior margin of the galeal incision is undermined posteriorly to provide additional length, to maximize the length of the pericranial flap. The pericranium is then incised above the superior temporal line on both sides and elevated as a separate layer attached to its vascular pedicle for later reconstruction and closure (Fig. 1B). Elevation of this layer allows exposure of the frontal
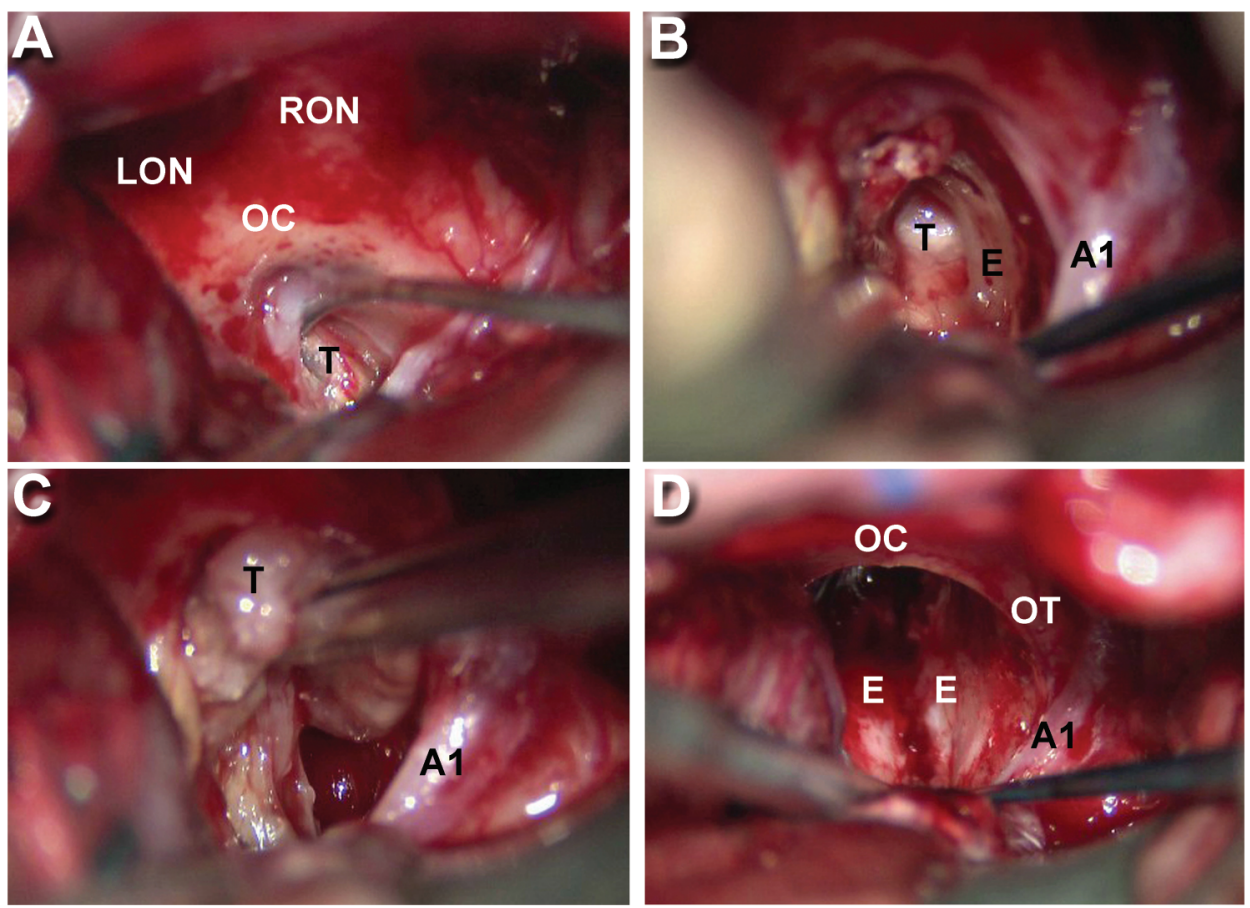

FIG. 4. Intraoperative photographs of intradural exposure and tumor removal achieved using the transbasal subfrontal approach. A: A right subfrontal corridor is exposed to visualize the optic nerves and chiasm. The lamina terminalis is opened sharply to identify the tumor capsule within the third ventricle. B: The ependyma of the ipsilateral wall of the third ventricle is well visualized from the midline orientation. This allows for dissection of the tumor capsule from the ependymal wall under direct visualization. C: The tumor capsule is gently delivered from a superior to inferior direction into the lamina terminalis corridor. D: After complete removal of the tumor, both ependymal surfaces of the third ventricle and hypothalamus are well visualized in the midline orientation. $A 1=A$ branch of right ACA; $E=$ ependymal wall of the third ventricle; LON = left optic nerve; $\mathrm{OC}=$ optic chiasm; OT = right optic tract; RON = right optic nerve; $\mathrm{T}=$ tumor. 
J. K. Liu et al.
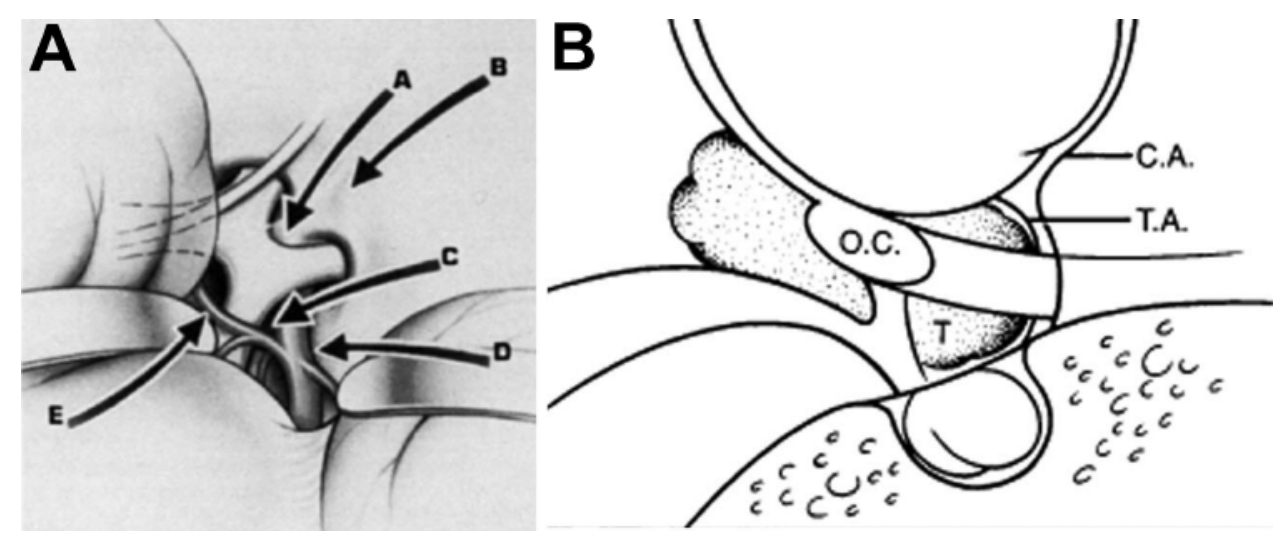

Fig. 5. A: Illustration showing the various corridors used to access craniopharyngiomas with the subfrontal approach, including subchiasmatic $(A)$, extension of the subchiasmatic by removing the tuberculum sellae and planum sphenoidale $(B)$, optico-carotid $(C)$, carotid-oculomotor $(D)$, and lamina terminalis $(E)$. B: Schematic drawing showing a sagittal view of tumor (T) arising in the suprasellar region, appearing beneath the optic chiasm (O.C.). The tumor is invested by a layer of arachnoid (T.A.) and is covered by cisternal arachnoid (C.A.). As the tumor grows, the layers may become fused over some or even most of the lesion's surface. The safest plane of dissection is between the tumor capsule and the tumor arachnoid. (Reprinted with permission from Carmel PW: Craniopharyngiomas, in Winn R (ed): Youmans Neurological Surgery, 5th ed. Philadelphia: W. B. Saunders, 2003. Copyright Elsevier.)

bone down to the orbital rims and nasion. The pericranial flap is wrapped in wet sponge to prevent dehydration, and reflected along with the scalp with the aid of hooks and rubber bands.

\section{Craniotomy Procedure}

A modified bifrontal transbasal craniotomy that incorporates the anterior wall of the frontal sinus is performed (Fig. 2). The inferior margin of the osteotomy is made through the anterior wall of the frontal sinus, starting at the nasofrontal suture and extending laterally over both orbital rims. This technique allows the bifrontal bone flap to extend as low as possible by following the contour of the anterior skull base in the coronal orientation. This modification provides an excellent line of sight to the anterior skull base, without any obstruction from bone overhang (Fig. 3). There is also an increased inferior-to-superior angle of attack to access the third ventricle. This also
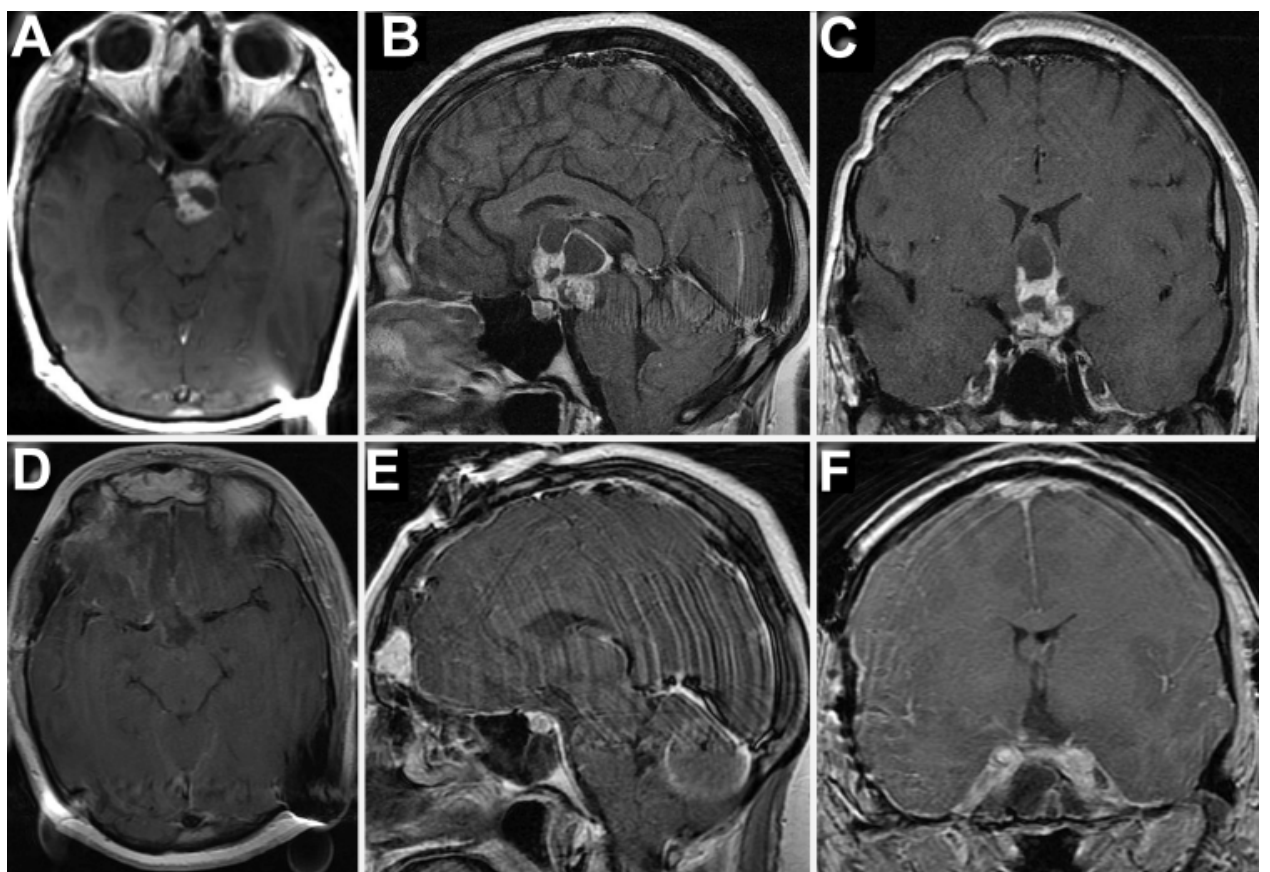

FIG. 6. Preoperative T1-weighted MR images with addition of Gd (A, axial; B, sagittal; C, coronal views) demonstrating a large retrochiasmatic craniopharyngioma with solid and cystic components. The tumor extends superiorly to the top of the third ventricle and inferiorly into the interpeduncular cistern and retrosellar region. Postoperative T1-weighted MR images with addition of $\mathrm{Gd}(\mathrm{D}$, axial; $\mathbf{E}$, sagittal; $\mathbf{F}$, coronal views) showing gross-total removal of the tumor after a transbasal subfrontal approach to the lamina terminalis. 


\section{Subfrontal translamina terminalis approach for craniopharyngioma}

obviates the need for any supraorbital rim removal, while minimizing brain retraction. The frontal sinus mucosa is exenterated and cranialized by removing the posterior wall of the frontal sinus. The nasofrontal ducts are packed with Betadine-soaked Gelfoam pledgets. Alternatively, autologous fat or muscle can be used here as well.

\section{Dural Opening}

The dura mater is incised on both sides of the SSS in a lateral-to-medial direction near the frontal base (Fig. 3). Care is taken not to violate any bridging veins. The frontal lobes are protected with cottonoid patties and the falx cerebri is identified. The anterior and inferior extent of the SSS is ligated using a pair of 2-0 silk suture ligatures, and then sharply divided toward the incisura of the falx cerebri. This allows final release of the bifrontal dura from the crista galli.

\section{Intradural Exposure and Tumor Removal}

A right subfrontal corridor is exposed to visualize the optic nerves and chiasm (Fig. 4). This is generally more advantageous for most right-handed surgeons, while sparing retraction on the contralateral frontal lobe. Although a unilateral subfrontal corridor is used, having a bifrontal craniotomy up front with division of the falx provides additional exposure to maximize the midline viewing angle, and increases the working corridor and angles of attack to the tumor. This also provides interhemispheric or bifrontal exposure to the lamina terminalis as alternative options.

The right frontal lobe is gently elevated and protected with cottonoid patties to identify the right olfactory tract, which is dissected from its attachments to the frontal lobe. The optic nerve and chiasm are identified and the chiasmatic and optico-carotid cisterns are opened up by using sharp dissection. The ICA and ACAs are identified. Care is taken to preserve the perforating vessels on the $A_{1}$ segment of the ACA. Adequate brain relaxation for the subfrontal corridor is achieved with intravenous mannitol, total intravenous anesthesia, and intraoperative removal of CSF from the cisterns during arachnoid dissection. If necessary, the lumbar drain can be opened for additional removal of CSF. The left frontal lobe will naturally fall away from the anterior skull base with the aforementioned brain relaxation techniques.

At this juncture, all possible routes to the tumor (including subchiasmatic, optico-carotid, and carotid-oculomotor) should be routinely inspected to see if there are any favorable corridors for tumor removal prior to opening the lamina terminalis (Fig. 5). In giant retrochiasmatic craniopharyngiomas that extend superiorly into the third ventricle, the tumor is often hidden from view behind the optic chiasm, and subsequent opening of the lamina terminalis is required. Tumor filling the third ventricle displaces the optic chiasm anteriorly and the optic tracts laterally, which can create the appearance of a prefixed chiasm. ${ }^{8,9}$

The lamina terminalis is opened sharply to identify the tumor capsule within the third ventricle (Fig. 4). A plane is then developed between the tumor capsule and the ependyma of the third ventricle. To deliver giant tumors through a relatively small window such as the lamina terminalis without injury to the visual apparatus, the surgeon must "make the tumor smaller" and deliver it in a piecemeal fashion. For solid components of the tumor, this can be accomplished with a precision-tip ultrasonic aspirator for central debulking and decompression of the tumor. For cystic portions of the tumor, gentle incremental aspiration of intracystic fluid allows decompression of the capsule while maintaining enough turgor of the cyst wall to separate the tumor capsule from the walls of the third ventricle. Once the tumor has been adequately debulked and decompressed, the tumor capsule can be gently delivered from a superior to inferior direction through the lamina terminalis (Fig. 4). The microsuction device in the surgeon's nondominant hand is used to help push the tumor down into the field and dissect the lesion off of the walls of the third ventricle while holding gentle traction on the capsule with tumor forceps in the dominant hand. Once the ventricular walls are identified, microcottonoid patties are used to protect the walls and maintain the plane of dissection between the ependyma and the tumor capsule. It is important not to amputate the tumor capsule prematurely and "lose the handle," whereby a remnant of the capsule will retract upward out of view from the lamina terminalis window. If the superior aspect of the lesion fails to deliver from the third ventricle, a transcallosal or transcortical transventricular approach can be used to remove the remaining intraventricular tumor.

Once the superior and posterior extensions of the intraventricular tumor have been delivered, attention is then directed to the remaining lesion within the infrachiasmatic and interpeduncular cistern. The Liliequist membrane forms the inferior boundary of the tumor in the interpeduncular cistern and becomes an important plane of dissection. Here, it is important to identify the "double" arachnoid layer and to distinguish the tumor arachnoid plane from the cisternal arachnoid plane (Fig. 5). The optimal and safest plane of dissection is between the tumor capsule and the tumor arachnoid, not the cisternal arachnoid plane. Early identification and preservation of this plane will facilitate the best chance at total removal of the lesion, and will spare the BA, PCAs, and $\mathrm{P}_{1}$ perforating vessels, which are protected by the Liliequist membrane. We therefore avoid bipolar cautery on the tumor capsule to prevent annealing of the arachnoid layers, and to preserve the subarachnoid plane of dissection.

The remaining portions of tumor are dissected from the undersurface of the optic apparatus by using sharp dissection. This area is often a blind spot for the surgeon working from this approach. Angled dental mirrors and angled endoscopes can be used to inspect the undersurface of the chiasm and median eminence for residual tumor. If tumor remnants or calcium fragments are densely adherent to the chiasm or the hypothalamus, these residual lesions are left behind to avoid risk of injury to these structures. Attempts should be made to identify and preserve the pituitary stalk. Although the stalk may be displaced, it can be located where it penetrates the diaphragma sellae to reach the pituitary gland. The stalk also has a unique striated appearance that represents the 
long portal veins that run parallel along its surface. ${ }^{8,9}$ At the end of the resection, one should be able to visualize the pituitary stalk, the oculomotor nerve, and bilateral $P_{1}$ segments of the PCAs through the opening of the lamina terminalis.

\section{Wound Closure}

The dura mater is reapproximated in a watertight fashion. After sectioning the SSS and falx cerebri, the dura often retracts posteriorly, and an interpositional dural graft substitute is used for closure. It is important to provide some redundant dura to accommodate for frontal lobe reexpansion and to prevent restriction if there is frontal lobe edema postoperatively. The Betadine-soaked Gelfoam pledgets are left in the nasofrontal ducts and cranialized frontal sinus. The vascularized pedicled pericranial flap is rotated posteriorly to occlude the frontal sinus cavity. The flap can be tacked down to the frontobasal dura with several interrupted dural sutures. The remaining redundant portion of the pericranium is unraveled to provide coverage over the frontal dural closure. The edges of the pericranium can be tacked to the bony edges of the craniotomy to hold it in place. When replacing the bone flap, care is taken not to constrict the vascular supply of the pericranium at the inferior margin of the bone flap. The remainder of the closure is performed in the standard fashion.

\section{Illustrative Case With Online Surgical Video}

History and Examination. This 29-year-old woman presented with 2 episodes of transient visual loss in both eyes. She had undergone a prior ventriculoperitoneal shunt placement and subtotal resection of a retrochiasmatic craniopharyngioma via an orbitozygomatic approach at another institution approximately 1 year previously. On examination, she exhibited no neurological deficits. A formal neuroophthalmological examination demonstrated no evidence of any visual field or visual acuity deficits. She was receiving hormone replacement therapy, including hydrocortisone, levothyroxine, and desmopressin acetate.

Magnetic resonance imaging (Fig. 6) demonstrated a large, recurrent, retrochiasmatic craniopharyngioma, with extension superiorly into the third ventricle up to the foramen of Monro, and extension inferiorly into the interpeduncular cistern. The tumor comprised both solid and cystic components and was primarily supradiaphragmatic in origin. There was no evidence of shunt malfunction or hydrocephalus.

Operation. The patient underwent a transbasal subfrontal craniotomy, as described above. A right-sided unilateral subfrontal approach to the lamina terminalis was performed. The lamina terminalis was opened up sharply to expose the tumor capsule. Initial decompression of the lesion was achieved by aspirating the fluid from its cystic portion. Further decompression was accomplished using ultrasonic aspiration for internal debulking of the solid components of the tumor. Once the tumor was adequately debulked, its capsule was carefully dissected away from both ependymal walls of the third ventricle and hypothalamus under direct visualization. The superior extent of the tumor capsule was brought down through the lamina terminalis with careful dissection. The remaining lesion in the interpeduncular cistern and infrachiasmatic region was carefully dissected off of the Liliequist membrane, with preservation of the BA and PCAs. A gross-total removal of the tumor was accomplished entirely through the lamina terminalis corridor, and both walls of the third ventricle were well visualized at the end of the surgery (Fig. 4).

Postoperative Course. Postoperatively, the patient was awake and alert, with no evidence of any neurological or visual deficits. Her endocrine status remained unchanged, requiring the same doses of hormones as had been prescribed preoperatively for replacement therapy. Postoperative MR imaging demonstrated gross-total removal of the tumor (Fig. 6).

\section{Discussion}

\section{Choice of Surgical Approach}

Several approaches have been proposed for removing retrochiasmatic craniopharyngiomas. These include midline transcranial (bifrontal transbasal, subfrontal, bifrontal interhemispheric), midline transnasal (transsphenoidal, extended transsphenoidal, endoscopic expanded endonasal), anterolateral (pterional, orbitopterional, orbitozygomatic), and posterior petrosal approaches (retrolabyrinthine, partial labyrinthine petrous apicetomy, translabyrinthine). Choosing the appropriate approach depends primarily on the location of the lesion and amount of tumor extension, and also to some degree on the surgeon's preference, comfort, and familiarity with the approach. The approach should provide adequate exposure that creates the shortest distance to the tumor with minimal brain retraction. Variations of each approach can be tailored to the individual patient by modifying the degree of bone removal. One should be ready to perform a combination of approaches for extensive lesions that cannot be adequately accessed via a single approach. For example, for craniopharyngiomas with significant intraventricular extension, a transcallosal or transcortical transventricular approach may be required in addition to a basal approach to the suprasellar region.

Retrochiasmatic craniopharyngiomas present a formidable surgical challenge because of their location behind and underneath the optic chiasm. Superior extension into the third ventricle and inferior extension into the interpeduncular cistern further increases the risk and complexity of the resection. With anterolateral approaches to the lamina terminalis, either pterional or orbitozygomatic, the angle of attack to the optic chiasm and lamina terminalis is oblique, and therefore prohibits visualization of the ipsilateral wall of the third ventricle and hypothalamus. This increases the risk of hypothalamic injury if adherent tumor is removed blindly without the ability to dissect the tumor off the hypothalamus under direct visualization. The superior viewing angle to the top of the third ventricle is also limited, although it is somewhat 
improved with an orbitozygomatic approach. ${ }^{15,25,33}$ In addition, access to the interpeduncular cistern and infrachiasmatic region through the optico-carotid and carotidoculomotor corridors can be narrow and is sometimes obstructed by perforating arteries. ${ }^{2}$

A transbasal subfrontal approach maximizes the lamina terminalis working corridor by maintaining a direct midline trajectory to the optic chiasm. In contrast to anterolateral approaches, in which the ipsilateral wall of the third ventricle is not well visualized, a midline transbasal approach provides excellent visualization of both walls of the third ventricle and hypothalamus (Fig. 4). Therefore, the tumor can be safely dissected from the ependymal walls under direct visualization. By maintaining a midline orientation, the tumor can be followed inferiorly into the interpeduncular cistern through the lamina terminalis exposure. Identification of the Liliequist membrane is critical because dissection between the tumor capsule and the tumor arachnoid permits total removal while preserving the arteries and perforating vessels that are protected by the Liliequist membrane.

Our modification of the bifrontal transbasal craniotomy (transbasal transglabellar) incorporates the anterior wall of the frontal sinus so that the inferior margin of the osteotomy extends as low as possible by following the contour of the anterior skull base in the coronal orientation (Fig. 4). By making the osteotomy at the nasofrontal suture below the glabella, there is no bone overhang that obstructs the line of sight to the midline anterior skull base. This exposure increases the inferior-to-superior viewing angle into the top of the third ventricle through the lamina terminalis, and minimizes the degree of brain retraction. By performing a bifrontal craniotomy and also bifrontal dural incision with division of the SSS and falx, the surgeon's line of sight is directly in the midline. The contralateral frontal lobe is spared from retraction, but will naturally fall away from the skull base during the operation, thereby increasing the working corridor and angles of attack to the tumor without obstruction by the falx cerebri. In unilateral subfrontal dural openings, the exposure is slightly off midline and slightly oblique because of the limitations of the falx. The area that is most difficult to visualize when using the subfrontal translamina terminalis approach is the region directly beneath the optic chiasm and nerves. Visualization of this area can be achieved with angled dental mirrors or angled endoscopes.

The transnasal transsphenoidal approach, on the other hand, can provide visualization of the infrachiasmatic area that is hidden from a transcranial view. This approach has generally been reserved for craniopharyngiomas that are primarily subdiaphragmatic in origin and accompanied by an enlarged sella turcica..$^{13,36,40}$ However, with advancements in transnasal approaches, such as extended transsphenoidal $1^{11,20,23,27}$ and endoscopic expanded endonasal approaches, ${ }^{7,22}$ suprasellar supradiaphragmatic craniopharyngiomas can be safely removed. Nevertheless, retrochiasmatic and also retroinfundibular craniopharyngiomas remain challenging to remove transnasally. ${ }^{22}$ They are often densely adherent to the diaphragm, major arteries, and perforating vessels, the pituitary stalk, and the walls of the third ventricle. Careful microdissection of these vital neurovascular structures via a transnasal approach can be difficult and at times precarious. ${ }^{36}$ Division of the diaphragma sellae increases the risk of a CSF leak: ${ }^{13,36}$ however, this has been largely reduced by using a vascularized nasoseptal flap for CSF leak repair. ${ }^{21}$ In addition, the pituitary gland often must be mobilized to improve suprasellar and supradiaphragmatic visualization, thereby increasing the risk of endocrine dysfunction. ${ }^{13,22}$

The transpetrosal approach to retrochiasmatic craniopharyngiomas was pioneered by Hakuba et al. ${ }^{17}$ and Al-Mefty and colleagues., ${ }^{1,2}$ These authors have favored this approach because it allows an upward projection to be used to dissect the upper pole of the tumor, with direct visualization of the hypothalamus and pituitary stalk. ${ }^{1,2}$ The disadvantages of this approach are prolonged temporal lobe retraction, potential injury to the vein of Labbé, technical difficulty in performing a mastoidectomy in young children with a nonpneumatized mastoid sinus, and also the aforementioned disadvantages associated with coming in from a lateral projection.

\section{Avoiding Complications}

Thorough knowledge of and attention to vital anatomical structures is of paramount importance to successful surgical removal of these tumors. Craniopharyngiomas can be densely adherent to the major arteries of the circle of Willis..$^{8,13}$ They receive their blood supply from perforating vessels of the PCoA and branches of the ICA that also supply the pituitary stalk..$^{8,40}$ The infundibulum can be significantly displaced, and should be identified on preoperative imaging during development of the surgical plan. Occasionally, however, the tumor arises from within the infundibulum and obliterates the stalk completely. ${ }^{22}$ Third ventricular anatomy can also be notably altered. Particular attention should be paid to the hypothalamus, mammillary bodies, velum interpositum, Liliequist membrane, and interpeduncular cistern.

Endocrinological dysfunction, ${ }^{4,17,30}$ hypothalamic dysfunction, ${ }^{2,34}$ death, ${ }^{2,29}$ and blindness ${ }^{4,40}$ are substantial adverse outcomes that must be discussed with the patient and family prior to surgery. Adequate hormone replacement is fundamental in decreasing morbidity, because the pituitary stalk is often intimately involved with the tumor capsule. $^{4-6,12,16,19,26,28,35,39}$

Significant morbidity can result from overly aggressive resection. Determining the extent of resection is a difficult task, but may save the patient from significant morbidity. Factors precluding complete resection include adherence to or invasion of the hypothalamus, ${ }^{13,36}$ location of the tumor, ${ }^{13,36}$ size of the tumor, ${ }^{13,37}$ consistency of the tumor, ${ }^{25,36}$ and more than $10 \%$ calcification. ${ }^{13}$ Despite the primary goal of total removal, it is important to know when to perform a subtotal resection after recognizing the aforementioned intraoperative findings that may risk permanent injury to critical neurovascular structures.

Standard microsurgical techniques should be used during the dissection of craniopharyngiomas. Maintaining the arachnoid planes will assist the surgeon in the dissection of the tumor capsule away from the neurovascular structures. The optimal plane of dissection is between the 
capsule and the tumor arachnoid. Additionally, optimal tumor debulking and cyst aspiration prior to dissection allows for greater mobility of the capsule wall and safer dissection, particularly when delivering large tumors through a relatively small window, such as the lamina terminalis.

\section{Conclusions}

The transbasal subfrontal approach provides direct midline access to the lamina terminalis for removal of retrochiasmatic craniopharyngiomas with third ventricular extension. By maintaining a midline orientation, excellent visualization of both walls of the third ventricle and hypothalamus as well as access to the interpeduncular cistern and retrosellar region can be achieved to permit total removal of these formidable tumors. The plane of dissection should be maintained between the capsule and the tumor arachnoid.

\section{Disclosure}

The authors report no conflict of interest concerning the materials or methods used in this study or the findings specified in this paper.

Author contributions to the study and manuscript preparation include the following. Conception and design: JK Liu, LD Christiano. Acquisition of data: LD Christiano, G Gupta. Analysis and interpretation of data: JK Liu. Drafting the article: JK Liu, LD Christiano, G Gupta. Critically revising the article: JK Liu, LD Christiano, PW Carmel. Reviewed final version of the manuscript and approved it for submission: JK Liu, LD Christiano, G Gupta, PW Carmel. Study supervision: JK Liu, PW Carmel.

\section{References}

1. Al-Mefty O, Ayoubi S, Kadri PA: The petrosal approach for the resection of retrochiasmatic craniopharyngiomas. Neurosurgery 62 (5 Suppl 2):ONS331-ONS336, 2008

2. Al-Mefty O, Ayoubi S, Kadri PA: The petrosal approach for the total removal of giant retrochiasmatic craniopharyngiomas in children. J Neurosurg 106 (2 Suppl):87-92, 2007

3. Ammirati M, Samii M, Sephernia A: Surgery of large retrochiasmatic craniopharyngiomas in children. Childs Nerv Syst 6:13-17, 1990

4. Baskin DS, Wilson CB: Surgical management of craniopharyngiomas. A review of 74 cases. J Neurosurg 65:22-27, 1986

5. Bertherat J, Carel JC, Adamsbaum C, Bougnères PF, Chaussain JL: [Endocrine evaluation and evolution of intrasellar craniopharyngioma (CPIS): study of 8 cases.] Arch Pediatr 1:886-893, 1994 [Fr]

6. Brauner R, Malandry F, Rappaport R, Pierre-Kahn A, Hirsch JF: [Craniopharyngioma in children. Endocrine evaluation and treatment. Apropos of 37 cases.] Arch Fr Pediatr 44:765-769, $1987[\mathrm{Fr}]$

7. Cappabianca P, Cavallo LM, Colao A, Del Basso De Caro M, Esposito F, Cirillo S, et al: Endoscopic endonasal transsphenoidal approach: outcome analysis of 100 consecutive procedures. Minim Invasive Neurosurg 45:193-200, 2002

8. Carmel PW: Craniopharyngiomas, in Winn R (ed): Youmans Neurological Surgery, 5th ed. Philadelphia: W. B. Saunders Company, 2003

9. Carmel PW: Tumours of the third ventricle. Acta Neurochir (Wien) 75:136-146, 1985

10. Cole C, Gottfried O, Gupta D, Couldwell W: Total intravenous anesthesia: advantages for intracranial surgery. Neurosurgery 61:369-377, 2007

11. Couldwell WT, Weiss MH, Rabb C, Liu JK, Apfelbaum RI, Fukushima T: Variations on the standard transsphenoidal approach to the sellar region, with emphasis on the extended approaches and parasellar approaches: surgical experience in 105 cases. Neurosurgery 55:539-550, 2004

12. de Vries L, Lazar L, Phillip M: Craniopharyngioma: presentation and endocrine sequelae in 36 children. J Pediatr Endocrinol Metab 16:703-710, 2003

13. Fahlbusch R, Honegger J, Paulus W, Huk W, Buchfelder M: Surgical treatment of craniopharyngiomas: experience with 168 patients. J Neurosurg 90:237-250, 1999

14. Garcia-Uria J: Surgical experience with craniopharyngioma in adults. Surg Neurol 9:11-14, 1978

15. Golshani KJ, Lalwani K, Delashaw JB, Selden NR: Modified orbitozygomatic craniotomy for craniopharyngioma resection in children. J Neurosurg Pediatr 4:345-352, 2009

16. Gonc EN, Yordam N, Ozon A, Alikasifoglu A, Kandemir N: Endocrinological outcome of different treatment options in children with craniopharyngioma: a retrospective analysis of 66 cases. Pediatr Neurosurg 40:112-119, 2004

17. Hakuba A, Nishimura S, Inoue Y: Transpetrosal-transtentorial approach and its application in the therapy of retrochiasmatic craniopharyngiomas. Surg Neurol 24:405-415, 1985

18. Hoffman HJ, De Silva M, Humphreys RP, Drake JM, Smith ML, Blaser SI: Aggressive surgical management of craniopharyngiomas in children. J Neurosurg 76:47-52, 1992

19. Honegger J, Buchfelder M, Fahlbusch R: Surgical treatment of craniopharyngiomas: endocrinological results. J Neurosurg 90:251-257, 1999

20. Kaptain G, Vincent D: Sheehan J, Laws ER, Jr.: Transsphenoidal approaches for the extracapsular resection of midline suprasellar and anterior cranial base lesions. Neurosurg 62:1264-1271, 2008

21. Kassam A, Thomas A, Carrau RL, Snyderman C, Vescan A, Prevedello D, et al: Endoscopic reconstruction of the cranial base using a pedicled nasoseptal flap. Neurosurg 63 (1 Suppl):ONS44-ONS53, 2008

22. Kassam AB, Gardner PA, Snyderman CH, Carrau RL, Mintz AH, Prevedello DM: Expanded endonasal approach, a fully endoscopic transnasal approach for the resection of midline suprasellar craniopharyngiomas: a new classification based on the infundibulum. J Neurosurg 108:715-728, 2008

23. Kouri JG, Chen MY, Watson JC, Oldfield EH: Resection of suprasellar tumors by using a modified transsphenoidal approach. Report of four cases. J Neurosurg 92:1028-1035, 2000

24. Lehrnbecher T, Müller-Scholden J, Danhauser-Leistner I, Sörensen N, von Stockhausen HB: Perioperative fluid and electrolyte management in children undergoing surgery for craniopharyngioma. A 10-year experience in a single institution. Childs Nerv Syst 14:276-279, 1998

25. Liu JK, Cole CD, Kestle JR, Brockmeyer DL, Walker ML: Cranial base strategies for resection of craniopharyngioma in children. Neurosurg Focus 18(6A):E9, 2005

26. Lyen KR, Grant DB: Endocrine function, morbidity, and mortality after surgery for craniopharyngioma. Arch Dis Child 57:837-841, 1982

27. Maira G, Anile C, Albanese A, Cabezas D, Pardi F, Vignati A: The role of transsphenoidal surgery in the treatment of craniopharyngiomas. J Neurosurg 100:445-451, 2004

28. Maira G, Anile C, Colosimo C, Cabezas D: Craniopharyngiomas of the third ventricle: trans-lamina terminalis approach. Neurosurgery 47:857-865, 2000

29. Maira G, Anile C, Rossi GF, Colosimo C: Surgical treatment of craniopharyngiomas: an evaluation of the transsphenoidal and pterional approaches. Neurosurgery 36:715-724, 1995

30. Merchant TE, Kiehna EN, Sanford RA, Mulhern RK, Thomp- 


\section{Subfrontal translamina terminalis approach for craniopharyngioma}

son SJ, Wilson MW, et al: Craniopharyngioma: the St. Jude Children's Research Hospital experience 1984-2001. Int J Radiat Oncol Biol Phys 53:533-542, 2002

31. Patterson RH Jr, Danylevich A: Surgical removal of craniopharyngiomas by the transcranial approach through the lamina terminalis and sphenoid sinus. Neurosurgery 7:111-117, 1980

32. Rutka JT: Craniopharyngioma. J Neurosurg 97:1-2, 2002

33. Schwartz MS, Anderson GJ, Horgan MA, Kellogg JX, McMenomey SO, Delashaw JB Jr: Quantification of increased exposure resulting from orbital rim and orbitozygomatic osteotomy via the frontotemporal transsylvian approach. J Neurosurg 91:1020-1026, 1999

34. Scott RM: Craniopharyngioma: a personal (Boston) experience. Childs Nerv Syst 21:773-777, 2005

35. Sklar CA: Craniopharyngioma: endocrine sequelae of treatment. Pediatr Neurosurg 21 (Suppl 1):120-123, 1994

36. Van Effenterre R, Boch AL: Craniopharyngioma in adults and children: a study of 122 surgical cases. J Neurosurg 97:3-11, 2002

37. Villani RM, Tomei G, Bello L, Sganzerla E, Ambrosi B, Re T, et al: Long-term results of treatment for craniopharyngioma in children. Childs Nerv Syst 13:397-405, 1997
38. Wang KC, Kim SK, Choe G, Chi JG, Cho BK: Growth patterns of craniopharyngioma in children: role of the diaphragm sellae and its surgical implication. Surg Neurol 57:25-33, 2002

39. Wang L, Zhao SF, Zhang W, Zhang MZ: Treatment of alternated water-electrolyte balance and endocrine status after removal of craniopharyngioma in adults. Chin Med J (Engl) 119:1348-1352, 2006

40. Yaşargil MG, Curcic M, Kis M, Siegenthaler G, Teddy PJ, Roth P: Total removal of craniopharyngiomas. Approaches and long-term results in 144 patients. J Neurosurg 73:3-11, 1990

41. Yaşargil MG, Reichman MV, Kubik S: Preservation of the frontotemporal branch of the facial nerve using the interfascial temporalis flap for pterional craniotomy. Technical article. J Neurosurg 67:463-466, 1987

Manuscript submitted December 14, 2009.

Accepted January 14, 2010.

Address correspondence to: James K. Liu, M.D., Department of Neurological Surgery, New Jersey Medical School, University of Medicine and Dentistry of New Jersey, 90 Bergen Street, Suite 8100, Newark, New Jersey 07101. email: james.liu@umdnj.edu. 